\title{
Smart Twins Bratislava and Vienna strategy
}

\author{
Milan Husar ${ }^{1}$, Vladimir Ondrejicka ${ }^{2}$ \\ \{milan.husar@stuba.sk¹, vladimir.ondrejicka@stuba.sk ${ }^{2}$ \}
}

Spectra Centre of Excellence, Slovak University of Technology in Bratislava, Vazovova 5, 81243 Bratislava, Slovakia ${ }^{1}$, Spectra Centre of Excellence, Slovak University of Technology in Bratislava, Vazovova 5, 81243 Bratislava, Slovakia $^{2}$

\begin{abstract}
The paper is focused on the smart city strategy for Bratislava and Vienna, the core of Vienna-Bratislava metropolitan region. The region is one of the most perspective in Europe, it is interface old and new European Union member states and creates the gate into Eastern Europe with high potential to become leader in innovations, research and development. Smart Twins strategy is a unique project attempting to create a strategic framework document offering vision and creating platform for cooperation. Study looks into the strategy preparation process and points at participatory and inclusive nature of the process. Team of local and foreign experts together with local stakeholders and municipality of Bratislava and Vienna were involved in strategy making. In the discussion part the limitations of project are deliberated together with potential of this project to improve the dialogue between Bratislava and Vienna in order to advancequality of life in the region.
\end{abstract}

Keywords: smart city, Bratislava and Vienna metropolitan region

\section{Introduction}

Vienna-Bratislava metropolitan region is located in Central Europe and is formed by two capital cities - Vienna and Bratislava, together accompanying more than 6.5 million people. It is located on the interface of old and new EU member states and creates a perspective metropolitan region with 2 million high-skilled workforce with more than 10 universities and educational institutions. In the beginning of 1990s, not long after the Iron Curtain was taken down, the German NGO Empirica [9] announced existence of agglomeration preconditions and in 2003, French DATAR [11] labelled the region as one of the most promising regions in the whole European Union (DATAR, 2003). Today, in 2016, the progress in the development of the region is rather stagnating. One of the reasons for this development is non-coordination of development efforts between the two poles of the region, Bratislava and Vienna. Smart city strategy produced by Vienna reflects this trend. The process of creating the Vienna Smart city strategy began in 2011 and the strategy was adopted in 2014 [8]. The strategy disregards the existence of spatial and strategic relationships with Bratislava and in a way deny this dimension of development. 
In the second half on 2016, Slovakia presides over the Council of the European Union. Most of the important meetings are taking place in Bratislava and it was one of the reasons why the city of Bratislava decided to commence the preparation of smart city strategy. To fully reflect the spatial and economic reality, it decided to include city of Vienna into the process and create Smart Twins Bratislava and Vienna strategy.

The city of Bratislava did not have document of this kind in the past. There were several strategic documents on city level (Climate change adaptation strategy, transportation, social and environmental studies etc.), however overall framework document covering holistic level of city territorial management was rather absent. This creates problems in coordination, in setting strategic and economic priorities for the city and one of the results in chaos in what the city needs to do over longer period of time. The goal was to create vision for the region for longer time excessing the traditional electoral period, to set strategic priorities for region's development. The idea was to set an image of smart, sustainable, inclusive and prosperous region with high quality of life for its citizens. To do so, the city decided for courageous step, to utilize an approach different than before, to prepare the strategy in participatory way, including a team of local and foreign experts and a wide range of local stakeholders.

The paper continues by theoretical foundations of smart city concepts and moves on to Twin Cities strategy. It lists the challenges in the preparation phase of the strategy and the main points of departure, then the strategy preparation is described and discussed.

\section{Smart City}

The push for smart cities was driven by increasing population rates in the world, by raising number of urban citizens, growing rates of urban sprawl [1], but at the same time increasing global competitiveness of cities in international arena for citizens and innovations [4]. To stay competitive in this aggressive struggle, cities are undergoing fundamental transformations. They question their management ideas and tools and reflect on how to survive or even thrive and develop in sustainable ways. Across the world, cities and metropoles challenge to compete to be the best models for sustainable development [4]. Rapid urbanization urges cities and creates imperatives for them to find smarter, more sustainable solutions to manage the challenges such as traffic congestions, air pollution, crime rates, challenges of waste management etc. [1]

Smart cities present an urban concept which is developed on the basis of utilizing social, economic and environmental capital [3]. The concept is about actively generating ideas in open, inclusive environment and transform cities often into living laboratories of urban innovations [4]. The objective is to reverse the challenges and threats and turn them into opportunities. The concept of smart city is a rising idea to mitigate and cure contemporary urban issues and create more sustainable cities [1].

In spite of wide-ranging discussion about the term smart city, there is no universally accepted definition [3]. The definitions of smart cities can be generally grouped into two categories, the ones focusing on technological side and the other perceiving technologies as one of the tools to 
create smart, sustainable cities by improving the efficiency of public management and use of resources.

Washburn et al [14] pioneers the technological view by stressing the use of smart computing technologies to make more intelligent, interconnected and efficient components of critical infrastructure. This view is emphasized by Anavitarte and Traty-Ryan [2] who highlight the role of modern information and communication technologies as enabling functioning of urban areas and providing efficient services to urban populations.

Less technological perspective is provided by Natural Resources Defense Council defining smart cities as striving to make itself smarter - efficient, sustainable, equitable and livable [13].

Finka et al [10] deliberate smart cities not so much about technologies rather as the ability to reflect and deal with multi-actor decision making and realted dilemmas in unpredictable environment. Giffinger et al [12] perceive smart cities as well performing systems forwardlooking in economy, people, governance, mobility, environment and living, built on the smart combination of endowments and activities of self-decisive, independent and aware citizens. Slightly different view provide Caragliu et al [7] putting emphasis on investment in human and social capital as well as technological stock fueling economic growth and quality of life with smart management of natural resources using participatory governance. The significant weight is in put on investment by city into human and social capital and becoming smart in these areas.

Alandwahi et al [1] identify the gap between the label 'smart' on many self-proclaimed urban projects while there is a lack of systematic research on understanding smart cities and what means to be smart. Another inconsistency is in using the term smart and other synonyms, such as intelligent or clever. Angelidou [3] elaborated a study on using the term smart city and came to conclusion that in literature 'smart' and 'intelligent' are used interchangeably. While Batty [5] uses smart, intelligent, information, virtual cities synonymously, it is possible to make distinctions here, too, for instance smart being more connected to technological point of view and intelligent to efficient use of resources. Similar discrepancies and disagreements in use of term further limit systematic research in this field.

Angelidou [3] studied literature on smart cities and came to following reasons why cities want to be smart and elaborate smart city strategies: to foster competitive economy, to be capable to foster innovation processes, citizen-centric governance resulting in smart city ecosystems, to manage urban problems of manageable size and respond to locally selected goals and to foster learning from cities with similar characteristics. As disadvantages are listed: competition for resources among small and medium cities against larger and better equipped cities, problems with aligning smart city strategies with multitude of policy agendas operating on city level, and the fact, that innovative pilot projects and small-scale developments not automatically guarantee effective acceptance and needed momentum on city scale.

\section{Smart Twins Bratislava and Vienna Strategy}

Smart Twins Bratislava and Vienna strategy set its goal to create a long term strategy for development of Bratislava with close relation to Vienna and its strategic priorities. To accomplish this, the city administration decided on unconventional way, to utilize the knowledge of local and foreign experts, to include into the process local stakeholders and people 
from the municipality, as well as representatives from Vienna who worked on Vienna smart city strategy.

City created an assignment with these high requirements and after public procurement Finlandbased private company was commissioned by the city of Bratislava to deliver such strategy in close collaboration with the city itself.

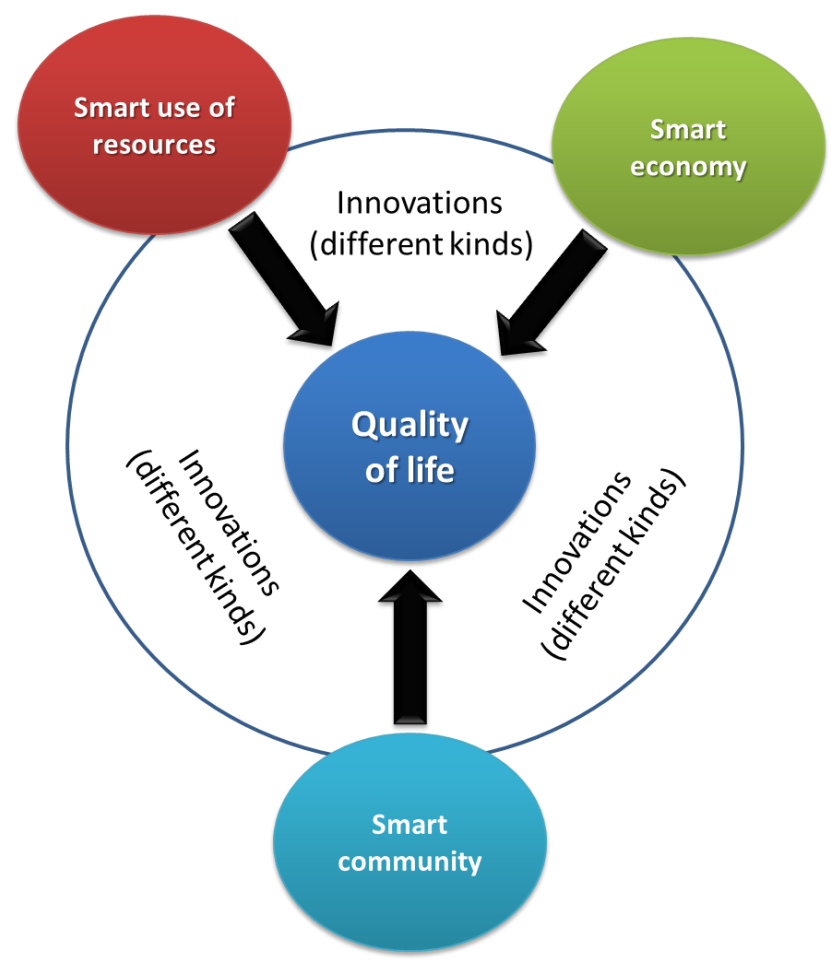

Figure 1: Smart Twins Bratislava and Vienna concept [6]

Two main objectives were defined as to create holistic, realistic strategy for the region and to make the plan preparation process participatory and inclusive to both local stakeholders and foreign and local experts.

Strategy is divided into two equally important parts, the smart city concept and a roadmap. Concept includes theoretical ideas in Bratislava and Vienna context, the vision and main priorities for the region. The roadmap includes concrete steps which need to be taken to achieve the vision and goals defined in the concept part.

The methodology of strategy making consisted of several steps. Initially, two groups of professionals were set up, the local and foreign experts. Local expert group consisted of university representatives and professionals from field of transportation, construction, economy etc. The foreign group of professionals was created by international experts from various economic fields, many of them with direct experience with smart city projects, mostly from 
Finland. The added value was the interaction of these experts which took place online on virtual platform, in which experts could meet, discuss and comment the project. Two content leaders were set up, one academic from Slovakia, the other from the United States who were looking after project from professional point of view.

The second step was to produce a definition of smart city, a theoretical concept which defined the priorities and direction of the project. To do so, both expert groups together with local stakeholders met during a workshop in Bratislava. The task was simple, to define what for them a smart city means. Local experts, local stakeholders, representatives from Vienna and discussion moderators were physically present, while foreign professionals took part virtually. The meeting took place in form of workshop in which participants were asked to work alone for a short time, then discuss their ideas and in the end in form of post-it notes to pin the ideas on flipchart sheet. These sheets were collected and created the basis for formulation of working definition of smart city for this project.

The second workshop took place the week after the first meeting. Unlike first meeting, the foreign experts had separate session due to technical difficulties and consequent delays which affected the first meeting. Local stakeholders and local experts met in Bratislava and discussed the possible challenges and solutions the region faces and which should be reflected in strategy. The same method of discussions and post-it notes was utilized as in the previous workshop.

Based on the inputs from both workshops and additional input of professionals (professional got assignment to elaborate their answers additionally in written form), local expert team produced the smart city concept which relies on three key points - smart use of resources, smart economy and smart communities (figure 1). Experts and stakeholders were able to comment and provide their remarks to the concept.

The vision was determined as being one of leading metropoles in Europe and integrative part of Central European Metropolitan Region with productive advanced knowledge - based economy and community, being able to attract and to create proper environment for creative class, for knowledge based economic activities, research as well as enterprises with high added value, for the development and spread of innovations, being competitive in offering optimal precondition for its inhabitants, for investors, entrepreneurs, visitors, tourists supporting their quality of life, efficient leadership and entrepreneurship, sustainable jobs market, creative friendly atmosphere, safety and security, equal access to high quality of services, transport means and networks with optimal modal split, high quality of environment with proper green and other public spaces supportive for healthy community life, transparent smart governance open for active social participation.

It is long and complex vision which follows the basic idea of the strategy, to include strategic goals across all policy fields and create a platform from which further initiatives grow. The concept of strategy further specifies targets to be achieved by the city of Bratislava by 2020, 2030 and 2050 as well as principles for policy fields to be followed. At the moment, the roadmap is in preparatory phase.

\section{Discussion}


The strategy was produced in non-conventional way from at least two reasons. First of all, the process was scheduled to take place in three months. For instance, Vienna smart strategy preparation took three years and to elaborate it separate public company owned by city of Vienna was set up. Secondly, the inclusionary approach is something unusual in Slovak context, especially considering the depth and breadth of participation process. More than 40 local and foreign experts participated together with tens of local stakeholders who could either in person during the meetings or virtually raise their questions and comments.

Bratislava as one of few European capitals did not have up until now its smart city strategy. As stated above, smart city is not seen technological solution rather as shift in paradigm of how the city is managed, focusing on smart use of resources, smart economy and last but not least the communities. As it is colloquially frequently mentioned, cities only become smart when people are smart [5], this signifies the feedback loop in understanding cities as complex systems in which it is important to listen to these feedback loops and to enable complex processes such as self-learning to take place.

The motivation for creating smart city strategy in this case is not only to check the field of having smart city strategy as it is currently trendy, but to set up the vision and priorities for long term period to lead the city and regional development in deliberated way.

\section{Acknowledgements}

This contribution is the result of the project implementation: SPECTRA+ No. 26240120002

"Centre of Excellence for the Development of Settlement Infrastructure of Knowledge Economy" supported by the Research \& Development Operational Programme funded by the ERDF and national grant scheme Vega 2/0038/14.

\section{References}

[1] Alawadhi, S., Aldama-Nalda, A., Chourabi, H., Gil-Garcia, J. R., Leung, S., Mellouli \& Walker, S. (2012, September). Building understanding of smart city initiatives. In International Conference on Electronic Government (pp. 40-53). Springer Berlin Heidelberg.

[2] Anavitarte, L., Tratz-Ryan, B. (2010) Market Insight: 'Smart Cities' in Emerging Markets. Gartner, http://gartner.com/id=1468734 www.

[3] Angelidou, M. (2014). Smart city policies: A spatial approach. Cities, 41, S3-S11.

[4] Bakıc1, T., Almirall, E., \& Wareham, J. (2013). A smart city initiative: the case of Barcelona. Journal of the Knowledge Economy, 4(2), 135-148.

[5] Batty, M. (2013). Big data, smart cities and city planning. Dialogues in Human Geography, 3(3), 274-279.

[6] Bratislava (2016) Smart Twins strategy.

[7] Caragliu, A., Del Bo, C., Nijkamp, P. (2011) Smart cities in Europe. Journal of Urban Technolo-gy, $18(2), 65-82$ 
[8] City of Vienna (2014) Smart City Vienna Framework Strategy. [online] available from: https://smartcity.wien.gv.at/site/files/2014/09/SmartCityWien_FrameworkStrategy_english_onepag e.pdf

[9] EMPIRICA (1993), Produktionsstandorte inWest- und Osteuropa - Ein Regionalführer für Investoren, EG, EFTA, Mittel- und Osteuropa (Bonn: EMPIRICA).

[10] Finka, M., Ondrejička, V., Jamečný, L. (2016) Urban safety as spatial quality in smart cities. Lecture Notes of the Institute for Computer Sciences, Social-Informatics and Telecommunications Engineering, LNICST, 166, pp. 821-829.DOI: 10.1007/978-3-319-33681-7 73,

[11] French Presidency (2000) Contribution to the debate on the long-term ESDP polycentric vision of the European space. Final report. Volume 2. Paris:DATAR,

[12] Giffinger, R., Fertner, C., Kramar, H., Kalasek, R., Pichler-Milanović, N., Meijers, E. (2007) Smart Cities: Ranking of European Medium-Sized Cities. Vienna, Austria: Centre of Re-gional Science (SRF), Vienna University of Technology

[13] NRDC (2016) National Research Defense Council. [online] available from: https://www.nrdc.org/issues/communities

[14] Washburn, D., Sindhu, U., Balaouras, S., Dines, R. A., Hayes, N. M., Nelson, L. E. (2010) Helping CIOs Understand "Smart City" Initiatives: Defining the Smart City, its Drivers, and the Role of the CIO. Cambridge, MA: Forrester Research, Inc. 